Situs Jurnal : $\underline{\text { http://ejurnal.stiepancasetia.ac.id/index.php/jieb }}$

Jilid 4 Nomor 1 Maret 2018

Hal 058 - 068

\title{
STRATEGI PEMASARAN UNTUK MENINGKATKAN PENJUALAN PADA CV. PARIS BANJARBARU
}

\section{Jaya Bahwiyanti* dan Sugiannor}

Abstract: The author conducted this research on CV. Paris Banjarbaru. The purpose of this research is to identify what strategy applied by $\mathrm{CV}$ company. Paris Banjarbaru and give a contribution of thought about marketing strategy that must be done in order to increase sales volume in CV. Paris Banjarbaru uses the theory of Philip Khotler Marketing Mix 7P. Data analysis technique used in this research is descriptive type of descriptive research is used if researchers want to give a more complete picture of a phenomenon, whether it is a phenomenon that is currently underway and phenomena that have occurred in the past. The result of research shows that the marketing strategy of Product, Place, Promotion and People has not been effective in increasing the sales volume in CV. Paris Banjarbaru.

Keywords: Marketing Strategy 7P: (Product, Price, Place, Promotion, People, Physical Evidence, Process

Abstrak: Penelitian ini bertujuan untuk mengidentifikasi strategi apa yang diterapkan oleh perusahaan CV. Paris Banjarbaru dan memberikan sumbangan pemikiran mengena Strategi pemasaran yang harus dilakukan agar meningkatkan penjualan pada CV. Paris Banjarbaru menggunakan teori dari Philip Kotler Marketing Mix 7P. Teknik analisa data yang digunakan dalam penelitian ini adalah secara deskriptif jenis penelitian deskriptif adalah digunakan jika peneliti ingin memberikan gambaran yang lebih lengkap mengenai suatu fenomena, baik itu fenomena yang sedang berlangsung saat ini maupun fenomena yang sudah terjadi di masa lalu. Hasil penelitian menunjukan bahwa belum efektifnya strategi pemasaran Product, Place, Promotion dan People dalam meningkatkan penjualan pada CV. Paris Banjarbaru.

Kata kunci : Strategi Pemasaran, Product, Price, Place, Promotion, People, Physical Evidence, Process

\section{Latar Belakang}

Pemasaran merupakan salah satu kegiatan pokok yang dilaksanakan pengusaha dalam aktivitasnya untuk mempertahankan keberlangsungan usahanya, supaya berkembang dan mendapatkan laba. Berhasil tidaknya dalam pencapaian tujuan bisnis tergantung keahlian pengusaha dibidang pemasaran, produksi, keuangan maupun bidang lain. Selain itu tergantung pula pada kemampuan pengusaha dalam mengkombinasikan fungsi-fungsi tersebut agar usaha perusahaan dapat berjalan lancar.

Pada dasarnya tujuan dalam mendirikan perusahaan adalah memperoleh laba semaksimal mungkin. Keberhasilan suatu perusahaan dalam mencapai tujuan sangat dipengaruhi strategi pemasaran yang tepat sesuai dengan kondisi pasar yang dihadapi. Keberhasilan strategi pemasaran dipengaruhi oleh beberapa faktor yaitu riset dan analisa pasar, keputusan tentang produk, penetapan harga, promosi dan distribusi (marketing mix).Agar berhasil dalam kondisi saat ini, diperlukan strategi pemasaran berorientasi pasar yang dapat mengantisipasi seluruh 
kainginan konsumen, untuk mengatasi ancama persaingan, dan memperkuat keunggulan bersaing. yang mencakup 7P (Product, Price, Place, Promotion, People, Physical Evidence, Process).

Ketujuh variabel tersebut merupakan kombinasi yang mempunyai peran yang sama dan merupakan satu kesatuan guna menunjang sukses perusahaan. Karena itu product, price, place, promotion, people, physical evidence, processdapat digunakan oleh perusahaan yang bersangkutan untuk menyusun strategi dasar perusahaan yang menjadi acuan bagi penyusunan strategi pemasaran yang efektif. Pada pelaksanaannya alat pemasaran (markrting mix) tersebut di lakukan secara berbeda-beda dan unik, tetapi tujuan akhir dari marketing mix tersebut adalah Deskripsikan perusahaan.

Perusahaan dalam bidang pertambangan adalah setiap kegiatan yang dilakukan dengan cara mengambil dan memanfaatkan semua bahan galian dari muka bumi yang mempunyai nilai ekonomi yang rangkaian kegiatannya dimulai dari penyelidikan bahan galian sampai pemasaran bahan galian. Seluruh tahapan kegiatan dalam rangka penelitian, pengelolaan dan pengusahaan mineral atau batubara yang meliputi penyelidikan umum, eksplorasi, studi kelayakan, konstruksi, penambangan, pengolahan dan pemurnian, pengangkutan dan penjualan, serta kegiatan pasca tambang.

CV. Paris Banjarbaru juga memberikan pelayanan lain seperti penjualan dan pengiriman pasokan batu gunung sesuai dengan kebutuhan konsumen. Semakin banyak bermunculan perusahaan-perusahaan pengelola tambang batu gunung di Kalimantan Selatan seperti CV. Batu Gunung Mulia yang berkantor di Binuang Kabupaten Tapin Hulu Sungai Selatan.Mengakibatkan penurunan dalam volume penjualan.

Tabel 1. Data Penyediaan Batu Gunung Pada CV. Paris Banjarbaru

\begin{tabular}{rcrrr}
\hline No & Tahun & Tersedia (Ton) & Terjual (Ton) & \multicolumn{1}{c}{ Sisa (Ton) } \\
\hline 1 & 2013 & 164.250 & 163.453 & 797 \\
\hline 2 & 2014 & 175.763 & 174.891 & 872 \\
\hline 3 & 2015 & 169.682 & 162.976 & 6.706 \\
\hline 4 & 2016 & 161.538 & 150.087 & 11.451 \\
\hline
\end{tabular}

Sumber Data:CV. Paris Banjarbaru

Berdasarkan data pada Tabel 1, penurunan penjualan terjadi dari tahun 2015 hingga 2016. Agar penjualan dapat meningkat untuk kemajuan perusahaan CV. Paris Banjarbaru maka diperlukan strategi pemasaran yang maksimal oleh perusahaan CV. Paris Banjarbaru dalam rangka mencapai tujuan perusahaan, Visi Misi perusahaan. CV. Paris Banjarbaru berusaha sedemikian rupa, membenahi dan memperbaiki yang telah diterapkan selama ini.

Berdasarkan fenomena yang telah dikemukakan, dapat diidentifikasi masalah yang akan diangkat dalam penelitian ini adalah sebagai berikut:

1. Bagaimana Strategi pemasaran yang selama ini untuk meningkatkan penjualan pada $\mathrm{CV}$. Paris Banjarbaru?

2. Bagaimana strategi pemasaran yang seharusnya digunakan untuk meningkatkan penjualan pada CV. Paris Banjarbaru?

\section{Kajian Literatur}

Menurut Kotler dan Keller (2014:5) Manajemen pemasaran adalah sebagai seni dan ilmu memilih pasar sasaran dan meraih, mempertahankan, serta menumbuhkan pelanggan dengan menciptakan, menghantarkan, dan mengkomunikasikan nilai pelanggan Wheelen and Hunger (2012:53) manajemen strategi adalah sekumpulan keputusan manajerial dan aksi pengambilan 
keputusan jangka panjang didalam perusahaan. Hal ini termasuk analisis lingkungan (lingkungan eksternaldan internal), formulasi strategi, implementasi strategi, dan evaluasi dan kontrol.

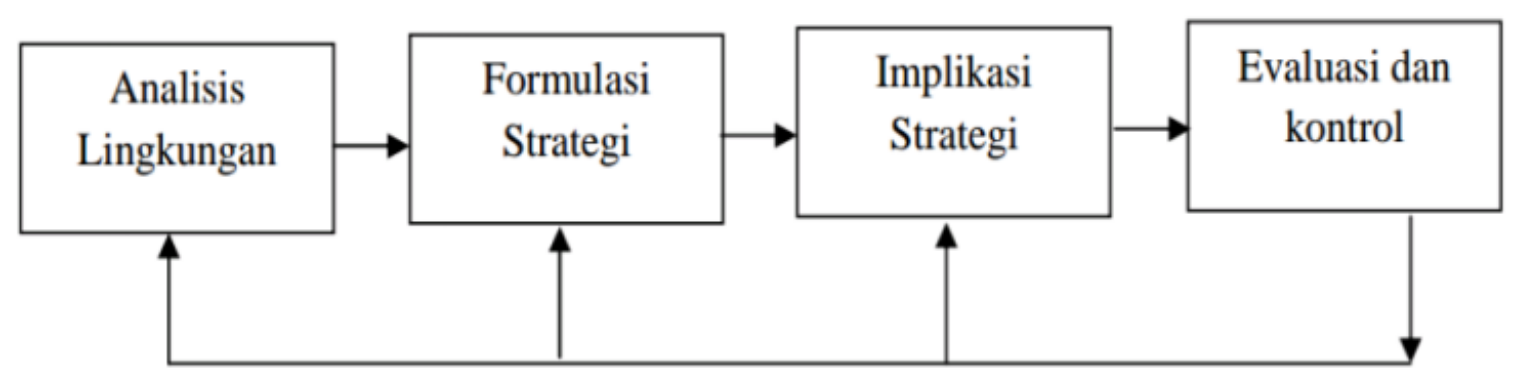

\section{Gambar 1: Tahapan Manajemen Strategi}

Sumber: Wheelen and Hunger (2012:63)

Strategi pemasaran yang dikembangkan perusahaan harus dapat memberikan gambaran dalam memanfaatkan peluang yang ada pada kegiatan pemasaran perusahaan. Pengertian strategi pemasaran menurut Kotler (2014:19) Strategi pemasaran merupakan pola piker yang akan di gunakan untuk mencapai tujuan pemasaran pada suatu perusahaan, bisa mengenai strategi spesifik untuk sasaran pasaran, penetapan posisi, bauran pemasaran, dan besarnya sebuah pengeluaran pemasaran. Tentang biaya pemasaran, bauran pemasaran, alokasi pemasaran dalam hubungan dengan keadaan lingkungan yang diharapkan dan kondisi persaingan. Dalam strategi pemasaran, ada tiga faktor utama yang menyebabkan terjadinya perubahan strategi dalam pemasaran yaitu:

1. Daur hidup produk

2. Posisi persaingan perusahaan dipasar

3. Situs Ekonomi

Bauran pemasaran menurut Kotler dan Armstrong (2014:76) unsur-unsur bauran pemaaran dapat di golongkan dalam empat kelompok dengan pengertian dari masing-masing Rangkaian variable atau unsur-unsur itu adalah :

1. Unsur produk (Product) adalah barang dan jasa perusahaan menawarkan dua target pasar.

2. Unsur harga (price) adalah jumlah pelanggan harus dibayaruntuk memperoleh produk.

3. Unsur Promosi (promotion) adalah mencakup perusahaan produk tersedia untuk menargetkan pelanggan.

4. Unsur Tempat (place) adalah mengacu pada kegiatan berkomunikasi kebaikan produk dan membujuk pelanggan sasaran.

Seiring dalam perkembangannya bauran pemasaran memiliki beberapa perangkat pemasaran tambahan seperti People (orang), Physical evidence (bukti fisik), dan Process (proses). Sehingga dikenal dengan istilah 7P maka dapat disimpulkan bauran pemasaran yaitu product, price, place, promotion, people, physical evidence dan process.

Adapun pengertian 7P menurut Kotler dan Amstrong dalam Tanzil (2014:7) yaitu:

1. Product (Produk) adalah mengelola unsur produk termasuk perencanaan dan pengembangan barang atau jasa yang tepat untuk dipasarkan dengan mengubah barang atau jasa yang ada dengan menambah dan mengambil tindakan yang lain yang mempengaruhi bermacammacam barang atau jasa. 
2. Price (Harga) adalah suatu sistem manajemen perusahaan yang akan menentukan harga dasar yang tepat bagi produk barang atau jasa dan harus menentukan strategi yang menyangkut potongan harga, pembauaran ongkos angkut dan berbagi variable yang bersangkutan.

3. Place (Tempat) yakni memilih dan mengelola lokasi perdagangan yang dipakai untuk menyalurkan produk tersebut dan juga untuk melayani pasar sasaran, serta mengembangkan sistem distribusi untuk pengiriman dan perniagaan produk secara fisik.

4. Promotion (Promosi) adalah suatu unsur yang digunakan untuk memberitahukan dan membujuk pasar tentang produk yang baru pada perusahaan melalui iklan, penjualan pribadi, promosi penjualan maupun publikasi melalui saluran media-media komunikasi seperti media massa, media cetak dan media elektronik.

5. People(Orang) adalah semua pelaku yang memainkan peranan penting dalam penyajian produk atau jasa sehingga dapat mempengaruhi persepsi pembelian. Elemen dari orang adalah pegawai perusahaan, konsumen dan konsumen lain. Semua sikap dan tindakan karyawan , cara berpakaian, dan penampilan karyawan memiliki pengaruh terhadap keberhasilan penyampaian produk atau jasa yang dijual

6. Physical evidence(Bukti Fisik) merupakan hal nyata yang turut mempengaruhi keputusan konsumen untuk membeli dan menggunakan produk yang ditawarkan. Unsur yang termasuk dalam secara fisik antara lain lingkungan atau bangunan fisik, peralatan, perlengkapan, logo, warna dan barang-barang lainnya

7. Process (proses) adalah semua prosedur aktual, mekanisme dan aliran aktivitas yang digunakan untuk menyampaikan produk. Elemen proses ini memiliki arti suatu untuk menyampaikan produk. Proses dalam produk merupakan faktor utama dalam bauran pemasaran seperti pelanggan produk akan senang merasakan sistem penyerahan produk sebagai bagian produk itu sendiri.

Menurut Swastha dan Sahaja (2014:246) penjualan adalah suatu proses pertukaran barang atau jasa antara penjual dan pembeli. Sedangkan menurut Kotler merupakan sebuah proses dimana kebutuhan pembeli dan kebutuhan penjual dipenuhi, melalui antar pertukaran informasi dan kepentingan". Adapun tujuan penjualan menurut Swasta dan Irawan (2012:32) mengemukakan bahwa suatu perusahaan mempunyai tiga tujuan dalam penjualan, yaitu:

1. Mencapai volume penjualan tertentu.

2. Mendapatkan laba tertentu.

3. Menunjang pertumbuhan perusahaan.

Sebagai fondasi untuk memperkuat penelitian ini, disajikan pula serangkaian penelitian terdahulu sebagai berikut:

1. Agus Susanto tahun 2013 dengan judul "Strategi Pemasaran guna meningkatkan volume penjualan pada PT. Madurejo". Hasil analisa dapat di simpulkan bahwa berdasarkan bauran pemasaran perusahaan PT. Madurejo dapat melakukan pemasaran dengan efektif dan efesien di karenakan sistem dan basis teknologi yang sudah terdukung, dan lokasi yang mendukung menjadi salah satu point lebih di hadapan konsumen. Perbedaanya dengan penelitian yang akan saya lakukan adalah menggunakan bauran pemasaran untuk meningkatkan volume penjualan pada $\mathrm{Cv}$. Paris Banjarbaru.

2. Meiriska Simamora tahun 2014 dengan judul "Strategi pemasaran untuk meningkatkan volume penjualan pada perusahaan batu kapur PT. Wira Kencana, 2014“. Mengindentifikasi faktor-faktor masalah yang membuat menurunya volume penjualan, dan hasilnya ada faktor kurangnya promosi yang mengakibatkan penurunan dalam volume penjualan. Perbedaannya 
dengan penelitian yang akan saya lakukan adalah perbedaan tempat, waktu dan masalah yang terjadi pada perusahaan Cv. Paris Banjarbaru.

3. Megasari Tahun 2011 dengan Judul "Analisa Strategi Pemasaran untuk meningkatkan penjualan pada perusahaan batu gunung Cv. Batu Agung Mulia". Tujuan penelitian ini untuk mengetahui Strategi pemasaran untuk meningkatkan penjualan pada perusahaan batu gunung $\mathrm{Cv}$. Batu Agung Mulia. Perbedaan dengan penelitian yang saya lakukan adalah menggunakan bauran pemasaran untuk meningkatkan volume penjualan pada $\mathrm{Cv}$. Paris banjarbaru.

\section{Metode Penelitian}

Penelitian ini bersifat deskriptif kualitatif. Penelitian deskriptif digunakan peneliti untuk memberikan gambaran yang lebih lengkap mengenai suatu fenomena, baik itu fenomena yang sedang berlangsung saat ini, maupun fenomena yang sudah terjadi di masa lalu. Peneliti dapat memberikan gambaran mengenai suatu keadaan saja atau bisa juga mendeskripsikan perkembangan dari keadaan tersebut.

Populasi dan sampel yang digunakan pada penelitian ini pada dasarnya dapat dijabarkan sebagai berikut:

1. Populasi, Menurut Sudjana (2010:6) Populasi adalah totalitas semua nilai yang mungkin, hasil yang menghitung/pengukuran, kuantitatif maupun kualitatif mengenai karateristik tertentu dari semua anggota kumpulan yang lengkap Populasi digunakan sebagai objek penelitian adalah Karyawan pada CV. Paris Banjarbaru sebanyak 38 orang.

2. Sampel, Menurut Sugiyono (2006:109) adalah bagian dari jumlah karateristik yang dimiliki. Sampel yang penulis gunakan adalah karyawan yang berjumlah 38 orang.

Penelitian ini terdiri dari 2 jenis data, yaitu:

1. Data Kuantitatif

Adalah data yang tidak diwujudkan dalam angka-angka melainkan penjelasan yang menggambarkan keadaan instansi.

2. Data Kualitatif

Data yang berhubungan dengan kategorisasi, karakteristik berwujud pertanyaan atau berupa kata-kata. Data ini biasanya didapat dari wawancara dan bersifat subjektif sebab data tersebut ditafsirkan lain oleh orang yang berbeda

Penelitian ini terdiri dari 2 jenis sumber data, yaitu:

1. Data primer

Data primer berupa informasi yang diterima langsung dari objek penelitian baik lisan suatu kenyataan atau fenomena.

2. Data sekunder

Data Sekunder, yaitu beberapa orang karyawan dari masing-masing bagian yang dipilih dengan cara purpossive sampling,terutama untukmengklariflkasi informasi dari masingmasing data primer.

Teknik pengumpulan data yang digunakan dalam penelitian ini yaitu:

1. Riset Kepustakaan(Library Research)

Yaitu penelitian yang dilakukan dengan cara mengumpulkan data-data dan bahan-bahan dari beberapa literature yang ada hubungan nya dengan permasalahan yang dibahas.

2. Riset Lapangan(Field Research)

Studi lapangan datang langsung pada objek penelitian untuk melakukan pengamatan dan meminta data yang diperlukan. Data-data tersebut diperoleh dengan cara : 
a. Pengamatan (Observation) yaitu pengumpulan data yang dilakukan dengan mengamati secara langsung pada objek yang diteliti untuk memperoleh gambaran yang lebih jelas tentang permaslahan yang akan dibahas.

b. Wawancara (interview) yaitu percakapan dalam maksud tertentu. Percakapan itu dilakukan oleh dua pihak, yaitu pewawancara yang mengajukan pertanyaan dan yang diwawancarai yang memberikan jawaban atas pertayaan tersebut.

c. Dokumentasi yaitu teknik mengumpulkan, meneliti, mempelajari dokumen, catatan dan laporan-laporan yang berhubungan dengan masalah yang akan diteliti dari dokumendokumen yang dimiliki oleh instansi.

\section{Hasil Penelitian dan Pembahasan}

Berdasarkan data pada Tabel 2, dapat dilihat data penjualan dari tahun 2013 hingga tahun 2017 pada CV.Paris banjarbaru. Dari tabel 3 dapat dilihat bahwa CV. Paris Banjarbaru mengalami penurunan penjualan dari tahun 2014 hingga 2017, penurunan volume penjualan terjadi hingga $-10,1 \%$.

Tabel 2. Data Penjualan Batu GunungPada CV. Paris Banjarbaru

\begin{tabular}{lrrr}
\hline Tahun & $\begin{array}{r}\text { Batu gunung } \\
\text { (Ton) }\end{array}$ & $\begin{array}{r}\text { Harga } \\
\text { (perton) }\end{array}$ & $\begin{array}{r}\text { Pendapatan } \\
(\mathrm{Rp})\end{array}$ \\
\hline 2013 & 163.453 & $\mathrm{Rp} \mathrm{62.000}$ & $\mathrm{Rp} \mathrm{10.134.086.000}$ \\
\hline 2014 & 174.891 & $\mathrm{Rp} \mathrm{62.000}$ & $\mathrm{Rp} \mathrm{10.843.242.000}$ \\
\hline 2015 & 162.976 & $\mathrm{Rp} \mathrm{62.000}$ & $\mathrm{Rp} \mathrm{10.104.512.000}$ \\
\hline 2016 & 150.087 & $\mathrm{Rp} \mathrm{62.000}$ & $\mathrm{Rp} \mathrm{9.305.394.000}$ \\
\hline 2017 & 148.331 & $\mathrm{Rp} .62 .000$ & $\mathrm{Rp} 9.196 .522 .000$ \\
\hline
\end{tabular}

Sumber Data :CV. Paris Banjarbaru

Tabel 3. Data Presentase Penjualan Pada CV. Paris Banjarbaru

\begin{tabular}{|c|c|c|c|c|}
\hline Tahun & $\begin{array}{l}\text { Batu gunung } \\
\quad \text { (Ton) }\end{array}$ & $\begin{array}{l}\text { Pendapatan } \\
\text { (Rp) }\end{array}$ & $\begin{array}{l}\text { Kenaikan/Penurunan } \\
\text { Penjualan (Rp) }\end{array}$ & $\begin{array}{l}\text { Presentase } \\
(\%)\end{array}$ \\
\hline 2013 & 163.453 & Rp 10.134.086.000 & - & - \\
\hline 2014 & 174.891 & $\operatorname{Rp} 10.843 .242 .000$ & 709.156 .000 & 6,5 \\
\hline 2015 & 162.976 & $\operatorname{Rp} 10.104 .512 .000$ & -738.730 .000 & $-7,3$ \\
\hline 2016 & 150.087 & Rp 9.305.394.000 & -799.118 .000 & $-8,5$ \\
\hline 2017 & 148.331 & $\mathrm{Rp} \quad 9.196 .522 .000$ & -108.872 .000 & $-1,1$ \\
\hline \multicolumn{3}{|c|}{ Rata- Rata } & -937.564 .000 & $-10,1$ \\
\hline
\end{tabular}

Sumber Data :CV. Paris Banjarbaru

Berdasarkan pada data yang telah dikemukakan pada Tabel 2 dan 3, serta dilengkapi dengan hasil wawancara dan observasi di lapangan, maka dapat dibuat pembahasan masalah sebagai berikut:

1. Strategi pemasaran yang selama ini dijalankan Pada CV. Paris Banjarbaru

a. Produc t(Produk)

CV. Paris Banjarbaru selama ini memproduksi Batu gunung yang diambil langsung dipertambangan desa Parangtali dan desa Sungai Langsat, dalam memproduksi terlebih dahulu dilakukan evaluasi tempat pertambangan yang sesuai untuk mendapatkan kualitas batu gunung yang baik dan tidak berdampak lingkungan dalam melakukan pertambangan. Kemudian batu gunung di keruk menggunakan excavator dan diproduk sesuai atau dikelompokan dengan kualitas besaran ukuran batu gunung sesuai dengan kebutuhan 
konsumen, batu gunung yang diproduksi CV. Paris Banjarbaru memiliki kualitas berdasarkan ukuran batu mulai dari 10:20 mm, 20:30 mm, 30:50 mm,dan kualitas sangat baik berukuran 10:40 $\mathrm{mm}$.

b. Price (Harga)

Harga merupakan nilai tukar yang bisa disamakan dengan uang atau barang lain untuk manfaat yang diperoleh dari suatu barang dan jasa bagi seseorang atau kelompok pada waktu tertentu dan tempat tertentu, harga digunakan untuk memberikan nilai finansial pada suatu produk maupun jasa. CV. Paris Banjarbaru selama ini memiliki harga penjualan yang bervariatif tergantung berat pembelian harga pun sewaktu-waktu dapat berubah, berikut daftar harga pada CV. Paris Banjarbaru :

Tabel 4. Daftar harga Batu Gunung CV. Paris Banjarbaru

\begin{tabular}{llr}
\hline Nama batuan & Satuan & Harga (Rp) \\
\hline Batu Gunung & Truk & 900.000 \\
\cline { 2 - 3 } & Pick up & 400.000 \\
\cline { 2 - 3 } & m3 & 185.000 \\
\cline { 2 - 3 } & Ton & 65.000 \\
\hline
\end{tabular}

Sumber : CV. Paris Banjarbaru

c. Place (Tempat)

Lokasi atau tempat suatu perusahaan dimana perusahaan itu melakukan kegiatan fisik. CV. Paris Banjarbaru berada di kota Banjarbaru provinsi Kalimantan Selatan, dengan alamat Jl. Palam Banjarbaru (Samping Komplek Pesona Modern). Lokasi pertambangan CV. Paris Banjarbaru terletak di desa parangtali dan desa sungai langsat kecamatan Simpang empat kabupaten Banjar.

d. Promotion (Promosi)

Promosi yang dilakukan CV. Paris Banjarbaru selama ini melakukan kerjasama dengan $\mathrm{CV}$ (Comanditaire Venotschap) yang membutuhkan batu gunung dalam menjalankan usahanya, seperti bekerjasama dengan perusahaan yang bergerak dalam bidang perumahan yang berada di Kalimantan selatan.

e. People (Orang)

Yang dimaksud people disini adalah orang yang berperan aktif dalam pelaksanaan kegiatan yang terjadi pada CV.Paris Banjarbaru, saat ini memiliki 38 Karyawan.

f. Physical Evidence (Bukti Fisik)

Merupakan penampilan fasilitas fisik seperti gedung dan ruangan pendukung serta tersedianya tempat parkir, kebersihan, kerapian, dan kenyamanan ruangan, kelengkapan peralatan komunikasi, dan penampilan karyawan.

g. Process (Proses)

Process pertambangan yang selama ini dilakukan CV. Paris Banjarbaru yaitu dengan melakukan tahapan-tahapan mulai dari awal Perencanaan tempat pertambangan, melakukan pengerukan, pemilahan Batu gunung dan mengkelompokan batu gunung (Berat, besar, dan kualitas) hingga menjual kepada konsumen.

1) Perencanan tempat pertambangan 
Perencanan yang mengacu kepada sasaran secara menyeluruh serta penentuan tempat melakukan perhitungan cadangan untuk setiap blok pengerukan batu gunung, penentuan cara, waktu, biaya dan resiko terhadap lingkungan sekitar.

2) Produksi

Memproduksi menyangkut teknik pengerjaan dan penggunanan sumber daya untuk mencapai sasaran dari dasar perencanaan secara ekonomis dan teknik. Pengerukan batu gunung akan menggunakan Excavacator dan Stone Cruseruntuk penghalusan batu gunung.

3) Pemilahan batu gunung

Pemilihan batu gunung berguna untuk menyesuaikan kebutuhan konsumen.

4) Penjualan

CV. Paris Banjarbaru melakukan penjualan di kantor yang beralamtkan di Jl. Palm Banjarbaru (samping Komplek Pesona Modern).

2. Strategi pemasaran yang seharusnya di gunakan CV. Paris Banjarbaru untuk menunjang upaya meningkatkan penjualan

a. Product (produk)

Dari segi produk CV. Paris Banjarbaru sudah memiliki kualitas produk yang bagus dikarenakan pengelompokan kualitas dan berat dari suatu batu,kualitas suatu batu gunung dapat diukur dari 10:20 mm, 20:30 mm, 30:50 mm dan 10:40 mm.Sehingga memudahkan konsumen dalam melakuakan pembelian batu gunung pada CV. Paris Banjarbaru.

b. Price (harga)

Harga (price) pada CV. Paris Banjarbaru sudah variatif dan dapat melakukan pembelian secara kecil maupun besar, dikarenakan CV. Paris Banjarbaru mematok harga pembelian untuk sasaran konsumen menengah hingga atas.

c. Place (Tempat)

Seharusnya CV. Paris Banjarbaru menambahkan identitas perusahaan didepan kantor seperti papan nama ataupun spanduk untuk memudahkan konsumen mencari alamat kantor pemasaran di CV. Paris Banjarbaru.

Dari segi tempat pertambangan CV. Paris Banjarbaru dari awal tahun 2008 hingga tahun 2017 melakukan pengerukan di 2 tempat yaitu di desa parangtali dan desa Sungai langsat, apabila melakukan pengerukan terus menerus ditempat yang sama akan mengakibatkan kerusakan lingkungan dapat kualitas produk akan menurun, hal ini dapat mengakibatkan kekecewaan konsumen dan menurukan volume penjualan, sebaiknya CV. Paris Banjarbaru melakukan pengevaluasian tempat pertambangan lagi seperti visi dan misi CV.Paris banjarbaru.

\section{d. Promotion (Promosi)}

Dari segi promosi CV. Paris Banjarbaru belum efektif dikarenakan promosi seperti spanduk, brosur atau pun iklan di media cetak maupun media social sangat jarang, ini mengakibatkan menurunnya volume penjualan setiap tahunnya, seharusnya CV. Paris Banjarbaru dapat melakukan promosi secara langsung antar individu atau persol sellinguntuk memacu perusahaan lebih mengenal pelanggan secara langsung sehingga berdampak pada terkumpulnya informasi motif pembelian terhadap konsumen dan dapat mempertahankan pelanggan secara komunikasi dua arah untuk tujuan awal meingkatkan penjualan. 
Seperti bekerjasama kepada perusahaan-perusahaan yang memang membutuhkan batu gunung dalam menjalankan usahanya seperti perusahaan perumahan yang mengunakan batu gunung untuk membuat pondasi rumah. Semakin banyak perusahan yang bekerjasama maka penjualan batu gunung pada CV. Paris Banjarbaru akan meningkatkan.

e. People (Orang)

Dari segi orang ataupun Karyawan dari CV. Paris Banjarbaru sudah terstruktur dengan bagus, hanya saja untuk CV. Paris Banjarbaru tidak memiliki sales yang melakukan promosi untuk bekerjasama terhadap perusahaan-perusahaan dan tidak adanya teknisi mesin alat berat apabila adanya kerusakan pada Excavator, Buldozer maupun truk pengangkut.

f. Physical Evidence (bukti fisik)

Dari segi bukti fisik CV. Paris Banjarbaru sangat kurang dikarenakan tidak adanya petunjuk jalan hingga tidak adanya papan nama perusahaan didepan kantor CV. Paris Banjarbaru, ini membuat konsumen sulit menemukan kantor dari CV. Paris Banjarbaru, seharusnya CV. Paris Banjarbaru bisa membenahi masalah untuk membuat papan nama agar memudahkan konsumen. Sedangkan dari pertambangan alat berat Stone Crusher (alat pemecah batu) pada CV. Paris perlu ditambah.

\section{g. Process (proses)}

Dari segi proses produksi CV. Paris Banjarbaru sudah sangat terencana dikarenakan adanya Divisi perencanaan untuk melakukan proses pertambangan dari awal mencari blok atau tempat pengerukan hingga proses pemilahan hingga penjualan terhadap konsumen, dan divisi lainya untuk membantu terlaksananya perencanan untuk mencapai sasaran yang dituju.

Adanya pertambangan batu gunung di sekitaran lingkungan masyarakat akan memberikan baik dampak positif maupun dampak negatif terhadap lingkungan hidup di sekitarnya, sebaiknya CV. Paris Banjarbaru dapat memperhatikan dampak postif dan dampak negative dari adanya pertambangan CV. Paris Banjarbaru:

1) Dampak positif

- Menambah pendapatan negara.

- Ikut meningkatkan perkembangan sosial, ekonomi, dan budaya daerah setempat.

- Memberi kesempatan kerja.

- Memberi kesempatan ahli teknologi.

- Menetapkan keamanaan dan kelestarian lingkungan.

2. Dampak negatif

- Mengubah morfologi dan fisiologi tanah (tata guna lahan).

- Merusak lingkungan karena:

- Hilangnya tanah subur.

- Vegetasi dibabat sehingga daerah menjadi gundul, maka mudah tererosi dan longsor.

- Flora dan fauna rusak, sehingga ekologinya juga rusak.

- Mencemari sungai.

- Polusi udara dan polusi suara.

- Dapat menimbulkan kesenjangan sosial, ekonomi dan budaya 


\section{Kesimpulan}

Berdasarkan pada serangkaian hasil penelitian dan pembahasan yang telah dikemukakan, maka kesimpulan pada penelitian ini adalah:

1. Strategi pemasaran yang selama ini diterapkan pada CV. Paris Banjarbaru adalah:

a. Product (Produk) CV. Paris Banjarbaru bergerak dibidang pertambangan batu gunung, ukuran batu dari 10:20 mm, 20:30 mm, 30:50 mm,dan kualitas sangat baik berukuran $10: 40 \mathrm{~mm}$

b. Place (Tempat) CV. Paris Banjarbaru berkantor di Jl. Palm Banjarbaru dan lokasi pertambangan di desa Parang tali dan desa Sungai Langsat

c. Promotion (Promosi) CV. Paris Banjarbaru melakukan promosi dengan melakukan kerjasama dengan perusahaan yang membutuhkan batu gunung sebagai bahan bakunya.

d. People (Orang) Struktur organisasi CV. Paris Banjarbaru dibagi menjadi empat divisi dan jumlah karyawan sebanyak 38 karyawan.

2. Strategi pemasaran yang seharusnya di terapkan CV. Paris Banjarbaru adalah:

a. Product (Produk) CV. Paris Banjarbaru dapat mempertahankan dan meningkatkan kualitas batu gunung yang diinginkan konsumen.

b. Place (Tempat) kantor CV. Paris Banjarbaru tidak memiliki Papan nama pada kantornya.

c. Promotion (Promosi) CV. Paris Banjarbaru dapat melakukan promosi di media cetak

d. People(Orang) CV. Paris Banjarbaru dapat menjalin kerjasama dengan perusahaan dan menambahkan karyawan di bagian sales dan tek nisi alat berat.

Saran-saran yang dikemukakan menyikapi hasil dari penelitian ini meliputi:

1. CV. Paris Banjarbaru sebaiknya menambahkan karyawan dibagian sales dan tenknisi alat berat.

2. Kantor CV. Paris Banjarbaru sebaiknya dapat diperbaiki dalam hal papan nama ataupun identitas kantor sebagai petunjuk untuk memudahkan konsumen.

3. Sebaiknya promosi pada CV. Paris Banjarbaru agar ditingkatkan, promosi dapat dilakukan pada media cetakmaupun media sosial.

4. CV. Paris Banjarbaru seharusnya menambahkan mesin Stone Crusher (Mesin pemecah batu).

5. Sebaiknya Divisi Perencanaan pada CV. Paris Banjarbaru lebih memperhatikan dampak positif dan negatif pada lingkungan sekitar pertambangan, dapat dilakukan dengan melakukan musyawarah dengan masyarakat sekitar lingkungan pertambangan.

\section{DAFTAR PUSTAKA}

Alma, Buchori, 2007, Manajemen Pemasaran dan Pemasaraan Jasa, Alfabeta, Bandung.

Assauri, Sofjan, 2014, ManajemenPemasaran, Raja GrafindoPersada, Jakarta Barat.

Buchori, HerryAchmaddanDjaslim Saladin, 2010, ManjamenPemasaran, Erlangga, Surabaya.

Febrianto, Aditya Indra, 2014, Penerapan Strategi Pemasaran pada CV. Jaya Jati Tambang Trosno Jawa Timur, Univesitas Islam Malang.

Hidayat, Khuzaimy, 2015, Analisis Strategi Pemasaran Pada CV Batu Alam Abadi di kota Prabumulih Sumatra Selatan, Fakultas Ekonomi Universitas Sriwijaya.

Jauch, Lawrence R dan Glueck William F, 2010, Manajemen Pemasaran, Erlangga, Jakarta.

Kotler, Philip, dan Garry Amstrong, 2014, Principles Of Marketing, New Jersey : Pearson Prentice Hall, USA.

Lupiyodi, Ramabt, 2013, ManajemenPemasaranJasa, Salemba, Jakarta. 
Megasari, 2011, Analisa Strategi Pemasaran untuk meningkatkan penjualan pada perusahaan batu gunung Cv. Batu Agung Mulia, Universitas Ahmad YaniBanjarbaru.

Salim, H.S, 2010, Hukum Pertambangan di Indonesia, Rajawali, Yogyakarta.

Simamora, Meiriska, 2014, Strategi pemasaran untuk meningkatkan volume penjualan pada perusahaan batu kapur PT. Wira Kencana, UniversitasLambungMangkurat.

Sudjana, Nana, 2010, Dasar-Dasar Proses Belajar, Sinar Baru, Bandung.

Sugiyono, 2010, Metode Penelitian Pendidikan Pendekatan Kuantitatif dan Kualitatif, Alfabeta, Bandung

Susanto, Agus, 2013, Strategi Pemasaran guna meningkatkan volume penjualan pada PT. Madurejo, SkripsiFaktor-Faktor yang memengaruhi volume penjualan, Universitas Islam Kalimantan Muhammad Arsyad Al-Banjary, Banjarmasin.

Suyanto, Muhammad, 2011, Strategi Pemasaran, Erlangga, Jakarta.

Swasta, Basu, 2014, ManajemenPemasaran Modern, BPFE, Yogyakarta.

Tanzil, Felycia Errina, 2014, Usulan Penelitian Peran Kepuasan Konsumen Dalam Memediasi Pengaruh Bauran pemasaran Terhadap Keputusan Pembelian Kebaya, Universitas Udayana, Denpasar. 